\title{
FOR THE 90TH ANNIVERSARY OF THE S. P. TIMOSHENKO INSTITUTE OF MECHANICS, NATIONAL ACADEMY OF SCIENCES OF UKRAINE
}

\author{
B. E. Paton
}

\section{Speech at the meeting in celebration of the 90th anniversary of the S. P. Timoshenko Institute of Mechanics, National Academy of Sciences of Ukraine (Kyiv, December 25, 2008)}

Dear participants:

Let me congratulate you all on this remarkable day - the 90th anniversary of the Institute of Mechanics named after Stepan Prokof'evich Timoshenko, the first technical institution of our Academy of Sciences.

The Institute staff has much to be proud of! The establishment and further development of the Institute were inseparably linked with many outstanding scientists, members of our Academy of Sciences, such as Stepan Prokof'evich Timoshenko, Dmitrii Aleksandrovich Grave, Konstantin Konstantinovich Siminskii, Sergei Vladimirovich Serensen, Nikolai Vasil'evich Kornoukhov, Fedor Pavlovich Belyankin Gurii Nikolaevich Savin, Anatolii Dmitrievich Kovalenko, Viktor Olimpanovich Kononenko, and other well-known mechanicians. From its first years, the Institute was actually at the foreground of academic mechanics in Ukraine.

It is pleasant to note that the Institute supports and develops the scientific schools established by these outstanding mechanicians. With time, the Institute of Mechanics "generated" scientists with the highest level of skill. Some of them became heads of different academic institutes, specialized chairs of higher educational institutions, and other responsible structures.

In their time, branches of the Institute of Mechanics served as the basis for establishing new academic institutes: Institute of Technical Mechanics in Dnepropetrovsk and Machine-Building Institute in Kharkov. The Institute's present research efforts in various areas of solid mechanics and general mechanics have been recognized internationally.

Note the impressive staff composition at the S. P. Timoshenko Institute of Mechanics. There are currently four academicians of the NASU, four corresponding members of the NASU, 64 doctors of science, and more than 90 doctors of philosophy.

Dear colleagues! Two days ago — on December 23-was the 130th anniversary of Stepan Prokof' evich Timoshenko's birth, the outstanding, world-famous mechanician, one of the 20 academicians who founded our Academy of Sciences, and the first director of the Institute bearing his name since 1993. We can fully regard this meeting as a tribute to his memory. Ninety years have passed since the forty-year old professor Timoshenko became the director of the Institute he founded.

Timoshenko's original credo still remains extremely relevant: he devoted his whole life to combining fundamental and deep knowledge of the science of strength and mechanical behavior and actual use of this knowledge to solve specific applied problems constantly posed by engineering practices.

It is very beneficial that many creative young people work at the Institute along with respectable members of our Academy of Sciences and competent doctors of science. Well-educated, talented, and diligent young people are working to prove themselves as scientists and make their contribution to mechanics. They give us hope and determine the future of academic mechanics in Ukraine. The Institute should further pay its major attention to the training and support of young, talented scientists.

Let me congratulate you all on this occasion once again and wish you good health and new achievements for the sake of science and for the benefit of our people and country. Thank you for your attention. 